\title{
Hydrodynamic reception in the Australian water rat, Hydromys chrysogaster
}

\author{
Wolf Hanke ${ }^{1} \cdot$ Sabine Meyer ${ }^{2} \cdot$ Horst Bleckmann $^{2} \cdot$ Guido Dehnhardt $^{1}$
}

Received: 12 September 2019 / Revised: 26 March 2020 / Accepted: 28 March 2020 / Published online: 18 April 2020

(c) The Author(s) 2020

\begin{abstract}
The Australian water rat, Hydromys chrysogaster, preys on a wide variety of aquatic and semiaquatic arthropods and vertebrates, including fish. A frequently observed predatory strategy of Hydromys is sitting in wait at the water's edge with parts of its vibrissae submersed. Here we show that Hydromys can detect water motions with its whiskers. Behavioural thresholds range from 1.0 to $9.4 \mathrm{~mm} \mathrm{~s}^{-1}$ water velocity, based on maximal horizontal water velocity in the area covered by the whiskers. This high sensitivity to water motions would enable Hydromys to detect fishes passing by. No responses to surface waves generated by a vibrating rod and resembling the surface waves caused by struggling insects were found.
\end{abstract}

Keywords Hydrodynamic reception · Rodent · Hydromys chrysogaster $\cdot$ Predation · Vibrissal system

\section{Introduction}

Many aquatic and semiaquatic mammals use their vibrissae to obtain information by directly touching and investigating unknown objects (Dehnhardt 1990, 1994; Dehnhardt and Kaminski 1995; Dehnhardt and Dücker 1996; Dehnhardt et al. 1998b; Catania et al. 2008). Harbour seals (Phoca vitulina) use their vibrissae to detect minute subsurface water motions (Dehnhardt et al. 1998a). Harbour seals (Dehnhardt et al. 2001; Wieskotten et al. 2010) and California sea lions (Gläser et al. 2011) can even follow the hydrodynamic trail left behind by a moving object. Similar to pinnipeds, many aquatic and semiaquatic mammals associated with fresh water habitats have vibrissae which they might also use to

Wolf Hanke and Sabine Meyer should be considered co-first authors.

Electronic supplementary material The online version of this article (https://doi.org/10.1007/s00359-020-01416-8) contains supplementary material, which is available to authorized users.

Wolf Hanke

wolf.hanke@uni-rostock.de

1 Sensory and Cognitive Ecology, Institute for Biosciences, University of Rostock, Albert-Einstein-Strasse 3, 18059 Rostock, Germany

2 Institute for Zoology, University of Bonn, Poppelsdorfer Schloß, 53115 Bonn, Germany detect prey-generated water motions. For instance, the African water rat Colomys goslingi, which hunts tadpoles and fish at night in shallow rivers, often sits at the waterside with its vibrissae immersed. Fish eating cats (Prionailurus viverrinus) show a similar behaviour (Seidensticker and Lumpkin 1991; Heydon and Ghaffar 1997), and otter civets (Cynogale bennettii) have been observed to hunt in the shallows of a river with their snout, which bears prominent vibrissae, positioned just above or below the water surface. American water shrews (Sorex palustris) attack the source of brief $(75 \mathrm{~ms})$ pulsed water movements, while experiments with live prey fish gave no indication that they pursue hydrodynamic trails (Catania et al. 2008).

The Australian water rat Hydromys chrysogaster (Fig. 1) inhabits river banks, lakes and sea shores (McNally 1960). Hydromys chrysogaster is an opportunistic predator which feeds on aquatic and semiaquatic insects, spiders, crustaceans, mussels, water birds and fish (McNally 1960; Woollard et al. 1978). Like many other fish hunting mammals, $H$. chrysogaster has well developed vibrissae which are densely innervated and possess a variety of morphologically different nerve endings (Dehnhardt et al. 1999). Based on results from confocal microscopy in Rattus norvegicus (Ebara et al. 2002), a fellow member of the rodent family Muridae, it may be assumed that at least eight different types of nerve endings are present also in Hydromys. However, vibrissal follicle-sinus complexes of $H$. chrysogaster are larger by about $60 \%$ and are more densely innervated by a factor of 

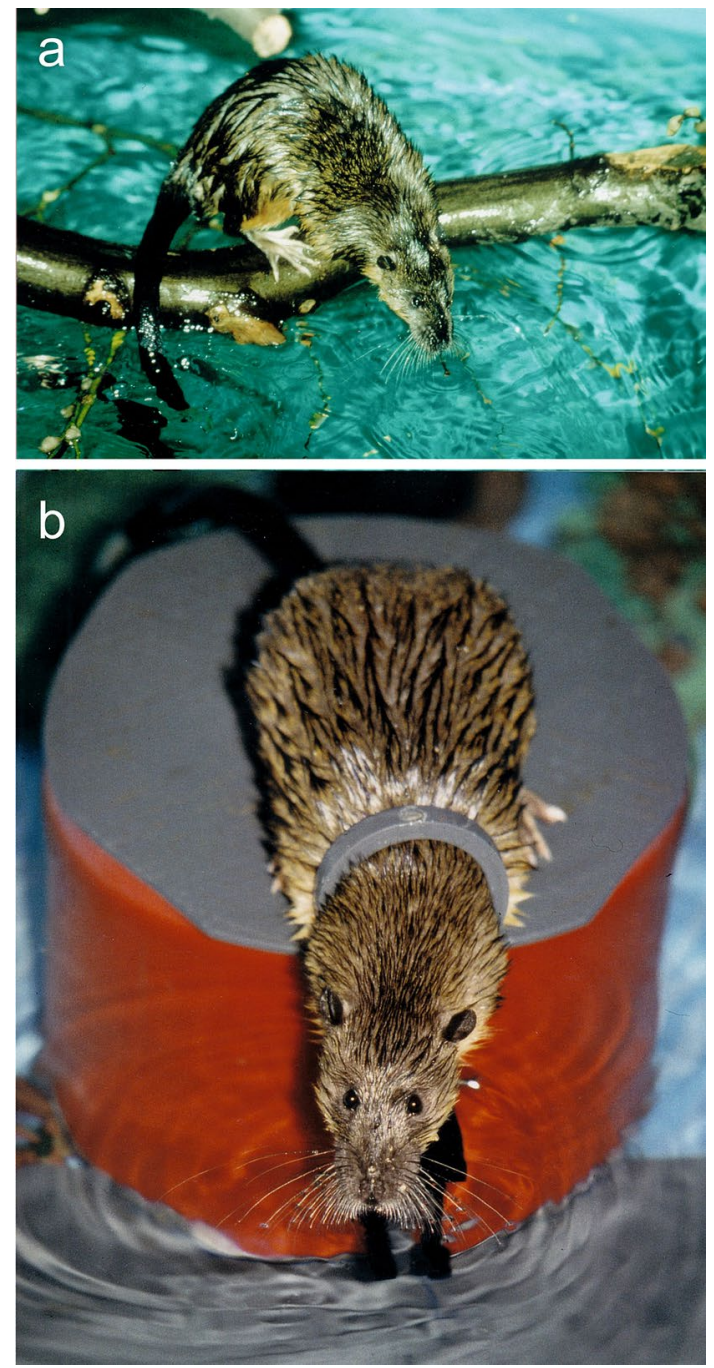

Fig. 1 The Australian water rat, Hydromys chrysogaster, performing its sit-and-wait behaviour with immersed vibrissae; a spontaneously in a near-natural environment, $\mathbf{b}$ induced to station in the experimental setup

at least 2.5 than the vibrissae of terrestrial rodents like $R$. norvegicus (Dehnhardt et al. 1999).

While in ambush, $H$. chrysogaster spreads out its vibrissae so that their tips are submerged (Fig. 1a). This behaviour, together with the observation that $H$. chrysogaster closes its eyes while swimming and diving, suggests that Australian water rats use their vibrissae for the detection of prey-generated water motions. Since Hydromys chrysogaster readily displays its natural sit-and-wait-behaviour under laboratory conditions (Fig. 1b), we tested this hypothesis in two psychophysical experiments with two different kinds of hydrodynamic stimuli. Hydrodynamic stimuli 1 (used in experiment 1) consisted of surface waves to mimic an insect struggling at the water surface, while hydrodynamic stimuli 2 (used in experiment 2 ) were generated by subsurface water motions to mimic a prey item below, but close to, the water surface. Hydrodynamic stimuli 2 involved subsurface and surface water flow as well as surface waves.

\section{Material and methods}

\section{Animals, housing and experimental pool}

Two female and one male Australian water rat, H. chrysogaster (Muridae), were used for the experiments. Animals were from the same litter and were bred and raised at the University of Bielefeld, Germany. In the following, the animals are designated with "Male 1", "Female 1" and "Female 2 ". At the beginning of the study, the water rats were about 6 months old. Body masses were between 800 and $1200 \mathrm{~g}$.

All three animals completed experiment 1. However, Female 2 died prior to experiment 2 . Therefore, only Male 1 and Female 1 completed the second experiment.

Animals were individually held in cages sized approximately $140 \mathrm{~cm} \times 80 \mathrm{~cm}$, each of which had a land and a water part (water depth $45-50 \mathrm{~cm}$ ). They were fed once a day with $60 \mathrm{~g}$ of shrimps, fish, mollusks, or cat food. Half of the food was given during experimental sessions and training.

Experiments were conducted in a separate circular indoor pool (diameter $1.5 \mathrm{~m}$, height $35 \mathrm{~cm}$ ) (Fig. 2a, b). The perimeter of the pool was enclosed by PVC plates to prevent the animals from escaping. Water depth was $24.5 \mathrm{~cm}$ in all experiments. An oval experimental platform was mounted in the middle of the pool $1 \mathrm{~cm}$ above the water surface. A stationing hoop (inner diameter 4.7 for the females and $5.4 \mathrm{~cm}$ for the male) was attached to the experimental platform; the animal was trained to place its head through the hoop to achieve a reproducible position (Figs. 1b, 2a, b). One water rat at a time was allowed to enter the pool for an experimental session and to haul out on the experimental platform. Water temperature in the pool and in the cages was 20 to $25^{\circ} \mathrm{C}$.

\section{Hydrodynamic stimuli 1 (pure surface waves)}

Water surface waves were produced with a rod mounted to a Ling mini shaker (Ling Dynamic Systems, Royston, UK, model 201/PA 25E) (Fig. 2a). Three different rods of diameters $0.5 \mathrm{~cm}, 2 \mathrm{~cm}$ and $3 \mathrm{~cm}$ were used to generate surface waves of different amplitude. Rods were $19.5 \mathrm{~cm}$ long and were immersed $2 \mathrm{~mm}$ into the water. Surface waves were generated by oscillating the rod vertically with the Ling mini shaker. The holder of the shaker rested on a separate platform to ensure that no unwanted vibrations were transmitted indirectly to the animals via the ground. The electronic signals driving the shaker were synthesized 

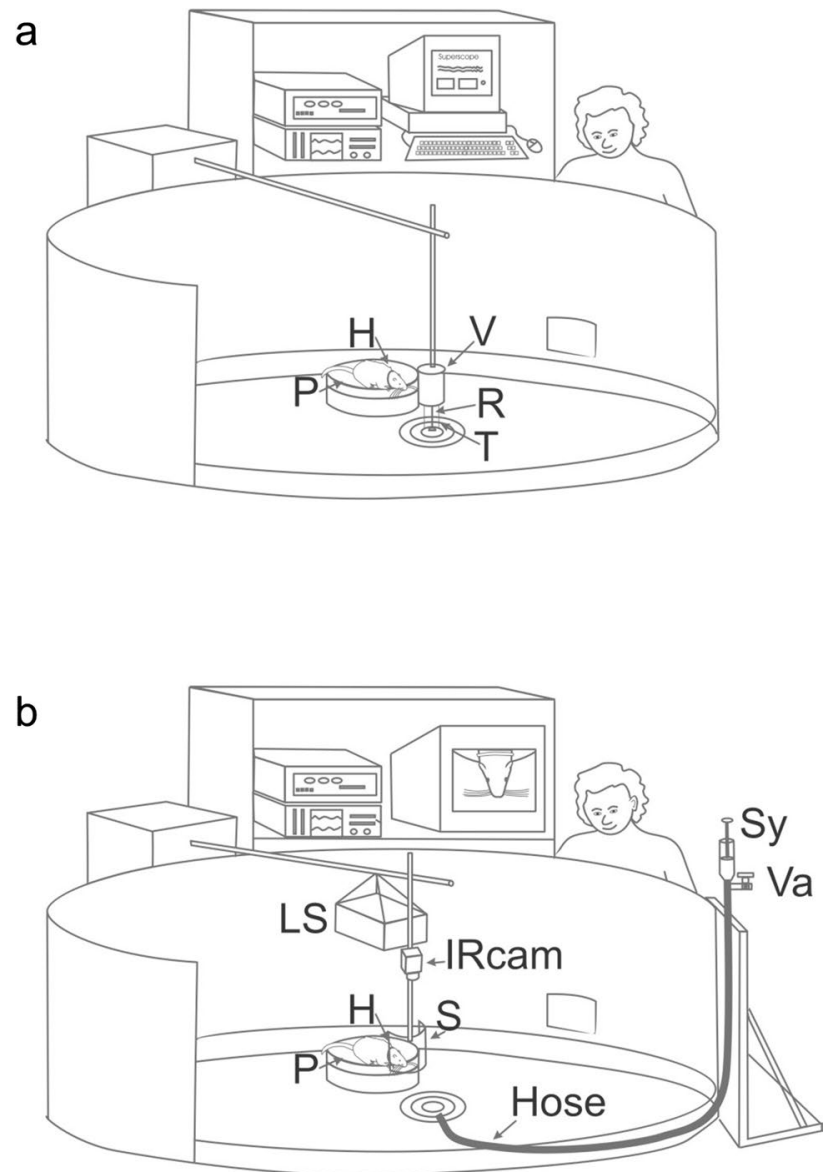

Fig. 2 Experimental setup for the application of stimuli 1 (a) and stimuli 2 (b). In both setups, the animal rested on a platform (P) $1 \mathrm{~cm}$ above the water surface and placed its head through a hoop (H, c.f. Fig. 1b) with the vibrissae immersed. a Stimuli 1: surface waves were generated with a rod (R) mounted to a vibrator $(\mathrm{V})$. A plastic tube $(\mathrm{T})$ that ended close to the water surface prevented the animal from seeing or touching the rod. b Stimuli 2: complex hydrodynamic stimuli were generated by letting water flow out of a hose (Hose) that ended $14 \mathrm{~cm}$ below the water surface. The stimulus was generated by the hydrostatic pressure of the water that had been sucked above the surface with a syringe (Sy), then released by opening a valve (Va). A hollow shield (S) prevented the animal from moving too close to the stimulus origin. An infrared camera (IRCam) recorded the animal and displayed it on a monitor. A loudspeaker (LS) above the animal delivered pink noise to mask acoustic cues

with a computer (Apple Power Macintosh IIci), output via a 14-bit DA-converter at a conversion rate of $20 \mathrm{kHz}$ (MacAdios II, GW-Instruments, Somerville, MA, sampling rate $10 \mathrm{kHz}$ ), and power amplified (Ling Dynamic Systems, model PA25E). To rule out that the water rats could sense the vibrating rod by directly touching it with the vibrissae or by visual cues, the portion of the rod that was above the water surface was encased in a plastic tube (outer diameter $6 \mathrm{~cm}$ ). With the software Superscope II 1.44 (GW-Instruments, Somerville, MA) and a custommade macro (M. Kettler, University of Bonn), frequency,
Table 1 Measured surface wave amplitudes for stimuli 1 (used in experiment 1 ); mean values of three stimulus repetitions

\begin{tabular}{ll}
\hline Frequency in $\mathrm{Hz}$ & $\begin{array}{l}\text { Mean p-p } \\
\text { amplitude } \\
(\mu \mathrm{m})\end{array}$ \\
\hline Single-frequency stimuli & 910 \\
10 & 690 \\
20 & 100 \\
40 & \\
Broadband stimuli & 115 \\
$0-50$ & 165 \\
$0-100$ & 210 \\
$0-200$ & \\
\hline
\end{tabular}

Amplitudes were averaged over the stimulus duration (excluding onset and offset times)

duration and amplitude of the generated surface wave stimuli could be varied at will. In this manner, singlefrequency sine wave stimuli $(10,20,30,40$ and $50 \mathrm{~Hz})$ and broadband noise stimuli (bandwidth $0-50 \mathrm{~Hz}, 0-100 \mathrm{~Hz}$, and $0-200 \mathrm{~Hz}$ ) were created. Broadband stimuli were used since they simulate, unlike single-frequency stimuli, natural, prey-generated surface waves (Bleckmann 1985a, b). Stimulus duration varied between 1 and $3 \mathrm{~s}$. To avoid stimulus onset and offset artefacts, rise and fall times of surface wave stimuli were adjusted to $250 \mathrm{~ms}$.

Surface waves were recorded with a receiver electrode (a chlorided silver wire of $200 \mu \mathrm{m}$ diameter) that was partly immersed into the water. The receiver electrode was placed at the location where the water rat would position its snout during an experimental session. A $10 \mathrm{~cm}$ long silver wire, submerged into the water, served as a reference electrode. The method of wave measurement was based on the principle that the electrical resistance between a fully submerged reference electrode and a partly immersed receiver electrode depends on the immersion depth of the latter. Resistance was measured with a Wheatstone bridge circuit (custom made, University of Bielefeld). The Wheatstone bridge circuit outputs a voltage (measured in $\mathrm{mV}$ ) that is transformed to surface wave amplitude based on the calibration curve for the system. To plot the calibration curve, the immersion depth of the receiver electrode was changed with a micromanipulator. During surface wave measurements no animals were present.

The results of surface wave quantification of stimuli 1 are summarized in Table 1. Figure 3 shows an example of a single-frequency surface wave (a) and a large bandwidth surface wave stimulus (b), recorded with a Wheatstone bridge circuit. The single-frequency surface waves used in the behavioural experiments had mean peak-to-peak displacement amplitudes $(n=3)$ of $910 \mu \mathrm{m}(10 \mathrm{~Hz}), 690 \mu \mathrm{m}$ $(20 \mathrm{~Hz})$, and $100 \mu \mathrm{m}(40 \mathrm{~Hz})$, respectively. For small or large bandwidth stimuli, maximal mean peak-to-peak amplitudes 


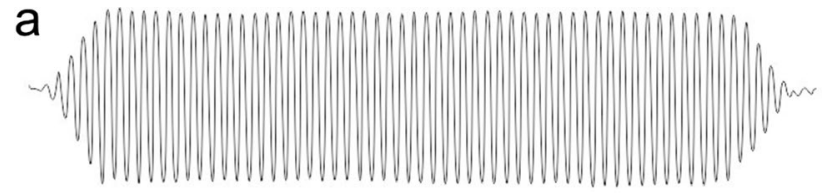

I $100 \mu \mathrm{m}$

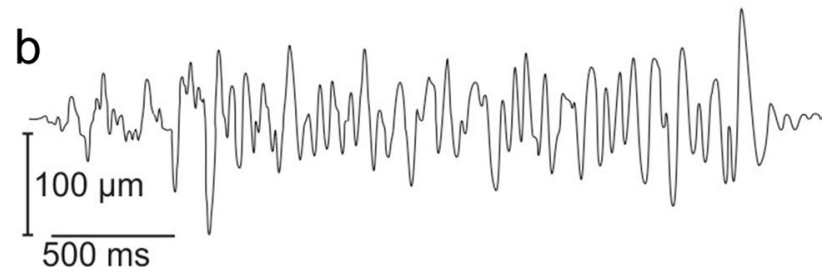

Fig. 3 Examples of water surface waves generated with a vibrating rod (stimuli 1, experiment 1 , detection of pure surface waves), quantified using an immersed wire connected to a Wheatstone bridge. a $20 \mathrm{~Hz}$ sine wave with rise and fall times of $250 \mathrm{~ms}$. b broad band surface wave stimulus

were $115 \mu \mathrm{m}(0-50 \mathrm{~Hz}), 165 \mu \mathrm{m}(0-100 \mathrm{~Hz})$, and $210 \mu \mathrm{m}$ $(0-200 \mathrm{~Hz})$, respectively.

\section{Hydrodynamic stimuli 2 (complex hydrodynamic stimuli)}

Complex hydrodynamic stimuli, including subsurface and surface water motions, were generated with a hose (inner diameter $1 \mathrm{~cm}$ ) that ended $14 \mathrm{~cm}$ below the water surface, $20 \mathrm{~cm}$ in front of the platform. The opening of the hose pointed towards the platform such that the angle between the hose and the water surface was $70^{\circ}$. The hose followed the bottom of the experimental tank and finally left the water to end $80 \mathrm{~cm}$ above the water surface (Fig. 2b). By means of a syringe, a defined amount of water could be sucked into the hose and above the water level, thus generating hydrostatic pressure. On opening a valve (No. 976, Gardena, Ulm, Germany), the water pressure was released and generated subsurface and surface water motions whose strength was a function of the hydrostatic pressure, i.e. of the height of the water column in the hose relative to the water surface in the experimental tank. The water velocity at the lower end of the hose could be varied at will by varying the height of the water column. The height of the water column could be adjusted with an accuracy of $0.5 \mathrm{~cm}$.

A custom-made particle tracking device was used to visualize and measure water movements. In particle image velocimetry and particle tracking velocimetry, water velocity is quantified by adding small buoyant particles to the water, illuminating a plane in the water using a fanned-out or moving laser beam, and recording a sequence of images with a camera from an angle perpendicular to the illuminated plane. Here, a horizontal plane $5 \mathrm{~mm}$ below the water surface was illuminated with an array of ten diode lasers ( $<5 \mathrm{~mW}$ each). The beam of each diode laser was passed through a glass rod that served as a cylinder lens and spread the beam in one direction, thus generating a light sheet approximately $1 \mathrm{~mm}$ thick and $100 \mathrm{~mm}$ wide. To visualize water movements, neutrally buoyant seeding particles (Vestosint 1101, Hüls AG, Marl, Germany; median diameter $100 \mu \mathrm{m}$ ) were seeded into the water. Pictures were taken from below with submerged CCD camera modules ( 0.2 lx, Conrad Electronic, Hirschau, Germany) that were equipped with VT objectives $(8 \mathrm{~mm}$, $f=1.2$ ). Pictures were recorded on VCR (Panasonic NV-F70 $\mathrm{HQ}$ ) at the time of the experiments. Videos were digitized post measurement using an LG V4745 video recorder whose signal was looped through a JVC SR-VS20 video recorder to obtain a Digital Video (DV) signal. Videos were processed using MatLab R2019b (www.mathworks.com) and Virtual Dub 1.10.4 (www.virtualdub.org), and particle velocities were measured using ImageJ 1.52a (https://www.imagej/nih. gov/ij). In this way, water velocities were related to the water column height that was used to generate stimuli 2. However, not only the particles in the laser light sheet $5 \mathrm{~mm}$ below the water surface, but also particles floating on the water surface were illuminated, the latter by reflected laser light with lower intensity. While this effect prevented the videos from being evaluated with correlation techniques as they are common in particle image velocimetry (PIV), it also offered the opportunity to measure water velocities in two different planes, namely the laser light sheet $5 \mathrm{~mm}$ below the water surface as well as the water surface itself. For details of the evaluation procedure and example movies of the water flow, see supplementary materials. Results are summarized in Table 2.

Hydrodynamic stimuli 2 included also surface waves, i.e. vertical surface movement. Figure $4 a-c$ shows the typical time course (left) and averaged frequency spectra (right) of surface waves $(n=20)$ generated by the water columns. Peak-to-peak displacement amplitudes of the surface waves, measured with the Wheatstone bridge circuit, were $6125 \pm 1329 \mu \mathrm{m}$ (height of water column $76.5 \mathrm{~cm}$ ), $1370 \pm 249 \mu \mathrm{m}(40 \mathrm{~cm}), 435 \pm 143 \mu \mathrm{m}(25 \mathrm{~cm})$, and $65 \pm 32 \mu \mathrm{m}(15 \mathrm{~cm})$. Surface waves reached the measurement location after $629 \pm 33 \mathrm{~ms}(76.5 \mathrm{~cm}), 724.5 \pm 38 \mathrm{~ms}$ $(40 \mathrm{~cm}), 974 \pm 67 \mathrm{~ms}(25 \mathrm{~cm}), 1394 \pm 87(15 \mathrm{~cm})$, respectively. Surface waves generated by the $5 \mathrm{~cm}$ and $10 \mathrm{~cm}$ water column were smaller than that and were below the resolution of our measurement device. Stimulus parameters for stimuli 2 (experiment 2 ) are summarized in Table 2 , along with the behavioural performance data.

\section{Animal training}

Animals were trained using operant conditioning and positive reinforcement, taking advantage of species-typical behaviour. Once they had settled on the experimental 


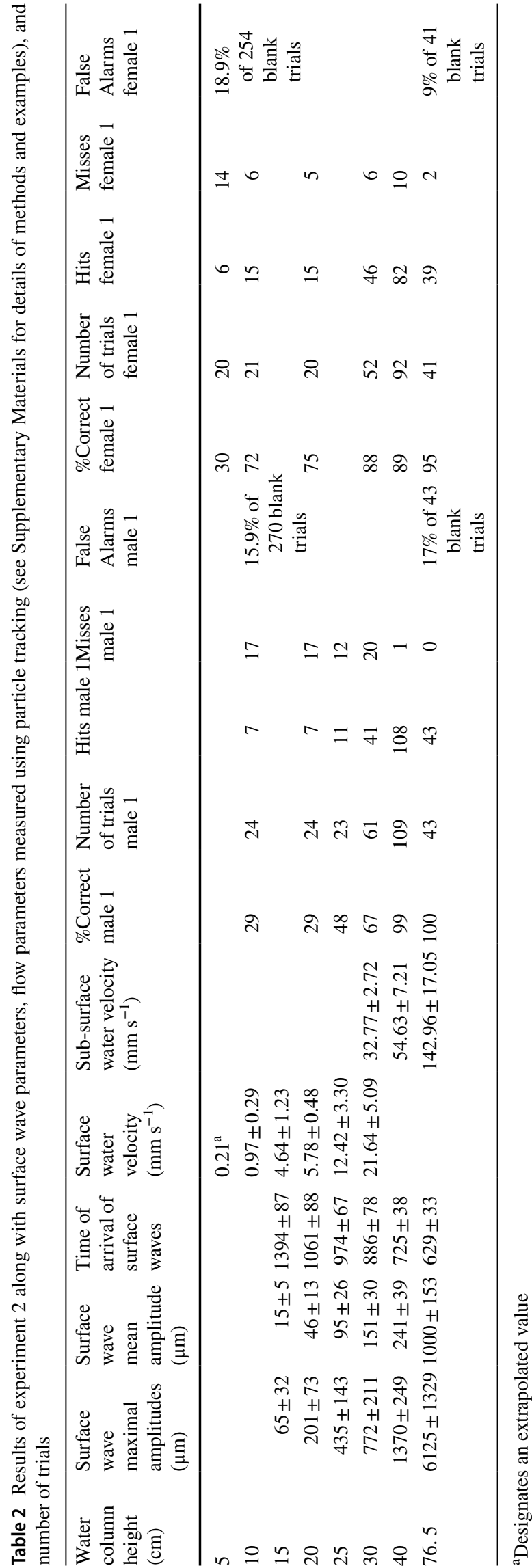

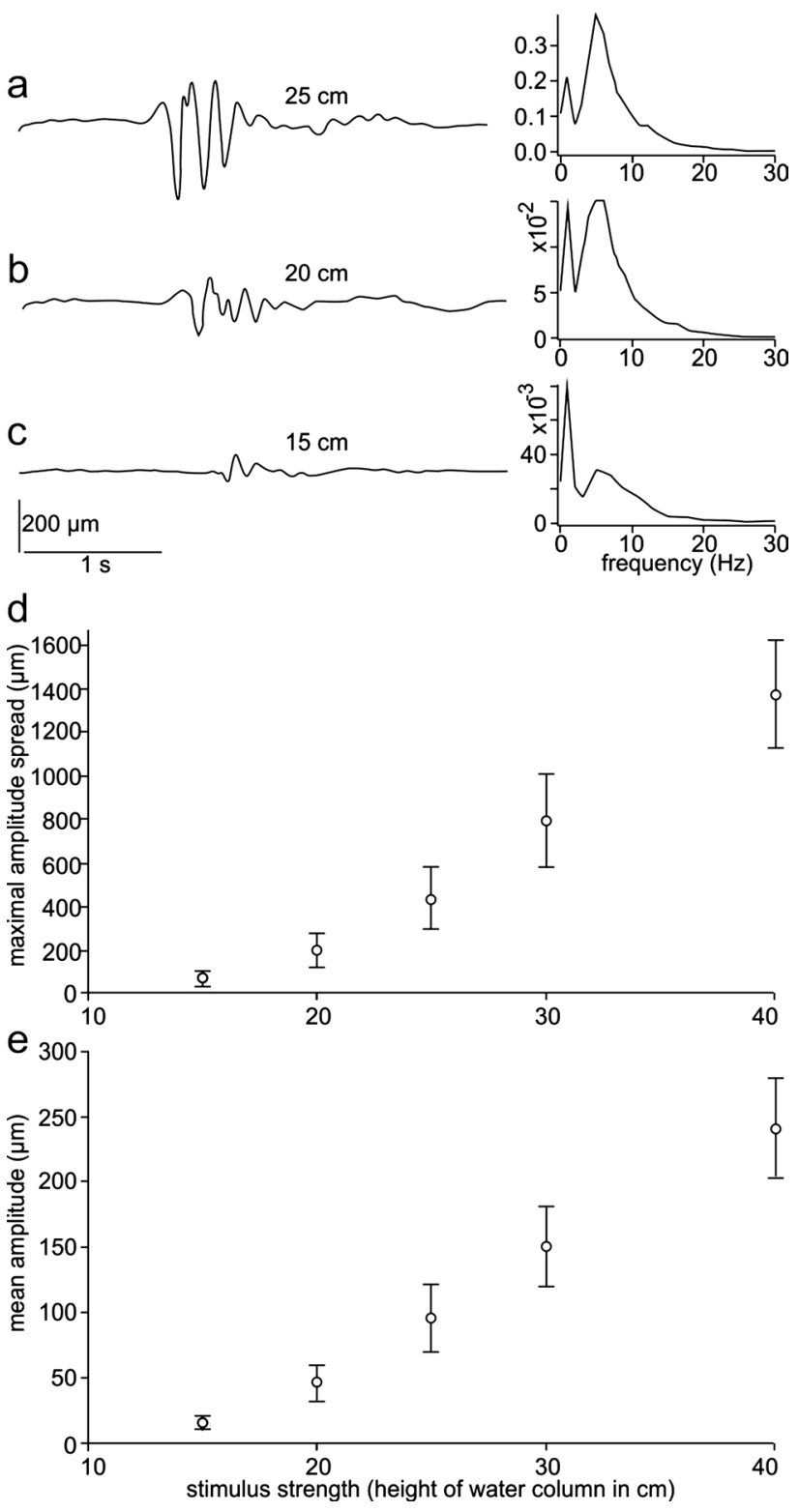

Fig. 4 Surface waves that were part of the complex hydrodynamic stimuli generated with a hose (stimuli 2, experiment 2, detection of complex hydrodynamic stimuli). a-c Examples of typical surface waves (left) and their frequency spectra (right). Spectra were averaged over 20 repetitions. Stimuli were generated with water column heights of $25 \mathrm{~cm}, 20 \mathrm{~cm}$, and $15 \mathrm{~cm}$, respectively. d Maximal amplitudes for water column heights from 15 to $40 \mathrm{~cm}$. e Mean amplitudes for water column heights from 15 to $40 \mathrm{~cm}$

platform (Figs. 1b, 2), the animals spontaneously scanned the water surface with their vibrissae using head movements. If the animal placed its head through the stationing hoop, food was presented with a tweezer. Once the animals had learned to place their head through the hoop, they had to remain in the hoop for a specified time that was gradually increased to $10 \mathrm{~s}$. After this time the experimenter gave a short high-frequency signal with a training whistle 
(secondary reinforcer). After the whistle signal, food was offered immediately (primary reinforcer).

In a second step, animals were trained to a go/no-go response paradigm: they had to leave the hoop (go response) when a hydrodynamic stimulus was presented manually with a rod or to stay in the hoop for at least $10 \mathrm{~s}$ (no-go-response) if no stimulus was presented. Correct behaviour was followed by the secondary and primary reinforcer. Initially, the animals received additional cues in the form of a verbal command or direct touch of the whiskers with the rod in case a go response was correct. All animals learned the go/no-go response quickly and maintained it after the additional cue was removed. In the initial experiments, visual or auditory cues were not masked, resulting in multimodal stimuli.

\section{Experimental procedure}

Animals were experimentally naive at the beginning of the study, and performed reliably in the go/no-go response paradigm with multimodal stimuli when testing began. Each experimental animal took part in two experimental sessions per day, each session consisted of up to 20 trials. Hydrodynamic stimuli were given only in about half of the trials. Trials with and without (blank trials) a hydrodynamic stimulus were performed in pseudorandom order (Gellermann 1933). At most three rewarded trials or three blank trials were presented in a row. On trials where a stimulus was given, it was delivered after the water rat had stationed in the hoop for at least $2 \mathrm{~s}$ (the time course of each trial was controlled with a digital stopwatch). Behavioural responses in trials where a stimulus was presented were scored as a "hit" (correct response) if the water rat left the hoop within $4 \mathrm{~s}$ after the valve had been opened (i.e. $6 \mathrm{~s}$ total stationing time in the hoop), and as a "miss" else. Behavioural responses in trials where no stimulus was presented were scored as a "correct rejection" if the water rat stayed in the hoop for $10 \mathrm{~s}$ total, and as a "false alarm" else. Hits and correct rejections were reinforced with the high-frequency whistle signal that had been established as a secondary reinforcer. Immediately after the whistle signal, the experimental animal was rewarded with food. Misses and false alarms were not reinforced. At the beginning of each experimental session, three warm-up trials were performed. These trials are not included in the data set. We started data collection only if at least two out of the three warm-up trials were successful. Otherwise, more warm-up trials were performed or the session was terminated.

To exclude visual cues, experiments were performed under infrared illumination. The water rats were filmed with an IR camera (CCD camera module No. 192589, Conrad Electronic, Hirschau, Germany) whose output signal was displayed on a TV monitor. To avoid any unwanted illumination, the monitor screen was shielded with black paper. The experimenter could, however, view the monitor through a small slit in the paper shield. To deliver a food reward, a light bulb was switched on.

To mask acoustic cues, pink noise $(0-20 \mathrm{kHz}$; sound pressure level $86.7 \mathrm{~dB}$ re $20 \mu \mathrm{Pa}$ ) was generated with a loudspeaker positioned above the experimental platform. The masker noise was not presented continuously throughout the session, but on each trial. The sound pressure level was measured near the stationing hoop with a hydrophone (Bruel \& Kjaer 8103) and a charge amplifier (Bruel \& Kjaer 2635).

Experiment 1, i.e. stimulation with pure surface waves (hydrodynamic stimuli 1), was conducted prior to experiment 2, i.e. stimulation with complex hydrodynamic stimuli (hydrodynamic stimuli 2). Both experiments were conducted to test whether the experimental animals responded to the respective type of stimulus at all. If this was the case, we determined the behavioural thresholds of the experimental animal.

Threshold measurements, as it turned out, were possible only with hydrodynamic stimuli 2 . During threshold measurements, the order of stimulus presentation followed the method of constant stimuli (Gescheider 1976). In each session, water column heights of $10 \mathrm{~cm}, 20 \mathrm{~cm}, 30 \mathrm{~cm}$, and $40 \mathrm{~cm}$ were presented in pseudorandom order, pseudorandomly mixed with an equal number of blank trials where no stimulus was presented. In addition, a $25 \mathrm{~cm}$ condition was used for Male 1 , and a $5 \mathrm{~cm}$ condition was used for Female 1. The strongest stimulus with a water column height of $76.5 \mathrm{~cm}$ was only used in the preceding stage of the study, and was not presented during threshold measurements.

\section{Results}

\section{Experiment 1: responses to stimuli 1 (pure surface waves)}

None of the three subjects showed a spontaneous response to single-frequency stimuli or to small or large bandwidth surface waves. To facilitate learning, an additional stimulus was introduced that indicated the presence of a hyrodynamic stimulus, with the intention to gradually remove the additional stimulus in the progress of the experiment ("fading" as in Terrace 1963) so that the hydrodynamic stimulus would gain control over the animal's response. Additional stimuli were a verbal command if single-frequency surface waves were applied, or touching the animal with a rod if large bandwidth stimuli were applied. However, while all animals quickly learned to apply the go/no-go response scheme in the presence of the additional stimulus, they did not respond to the hydrodynamic stimulus alone once the additional stimulus was removed. After at least 4 weeks of training with no improvement, training to stimuli 1 was terminated. 


\section{Experiment 2: responses to stimuli 2 (complex hydrodynamic stimuli including horizontal flow and vertical surface waves)}

In the first set of experiments with stimuli 2, we presented water motions generated with a $76.5 \mathrm{~cm}$ water column (76.5-cm-stimulus). In the area covered by the animal's vibrissae maximal water velocity was $143 \mathrm{~mm} \mathrm{~s}^{-1}$, measured $5 \mathrm{~mm}$ below the water surface.

Both experimental animals responded spontaneously to this stimulus. While Male 1 showed a strong avoidance reaction in the very first trial, Female 1 spontaneously moved its head in the direction of the stimulus source. During four consecutive days, the two animals tested in this condition responded strongly in nearly all of the trials in which a stimulus was presented (Male 1, 100\% of 43 trials; Female 1, 95\% of 41 trials). False alarm rates were 17\% (Male 1, 43 blank trials) and 9\% (Female 1, 41 blank trials).

In a second set of experiments with stimuli 2, psychometric functions for both animals were assessed using water column heights from 5 to $40 \mathrm{~cm}$ (see methods and Table 2). Psychometric functions are shown in Fig. 5. To plot these functions, water velocity measured using the floating particles rather than surface wave amplitude measured using the Wheatstone bridge was taken as the presumably more relevant parameter of the hydrodynamic stimulus, taking into account that stimuli 1 , which consisted of pure surface waves, had failed to elicit any response in the three animals used in experiment 1 . Both experimental animals responded reliably to water velocities of $55 \mathrm{~mm} \mathrm{~s}^{-1}$. Hit rate was $99 \%$ (Male 1) and $89 \%$ (Female 2), respectively. A Weibull function was fitted to the data to obtain the $75 \%$ and the $50 \%$ response threshold for both animals, i. e. the interpolated stimulus intensity to which the animals responded in $75 \%$ or $50 \%$ of the stimulus trials. $75 \%$ response thresholds were $20.8 \mathrm{~mm} \mathrm{~s}^{-1}$ (Male 1) and $6.2 \mathrm{~mm} \mathrm{~s}^{-1}$ (Female 1). 50\% response thresholds were $9.4 \mathrm{~mm} \mathrm{~s}^{-1}$ (Male 1) and $0.4 \mathrm{~mm} \mathrm{~s}^{-1}$ (Female). The 50\% threshold for Female 2, however, is influenced by one water velocity value (the value for the $5 \mathrm{~cm}$ water column) that could not be measured directly and was obtained from extrapolation. More conservatively, we assume a 50\% threshold of $1.0 \mathrm{~mm} \mathrm{~s}^{-1}$ water velocity for Female 2, the velocity where the animal responded correctly in $52 \%$ of the stimulus trials.

Mean response latencies, defined as the time from the opening of the valve to the response of the animal, were between 2 and $3 \mathrm{~s}$ for Male 1 in all stimulus conditions (7-41 trials per stimulus condition), and between 1 and $2 \mathrm{~s}$ for Female 1 in all stimulus conditions (6-32 trials per stimulus condition).
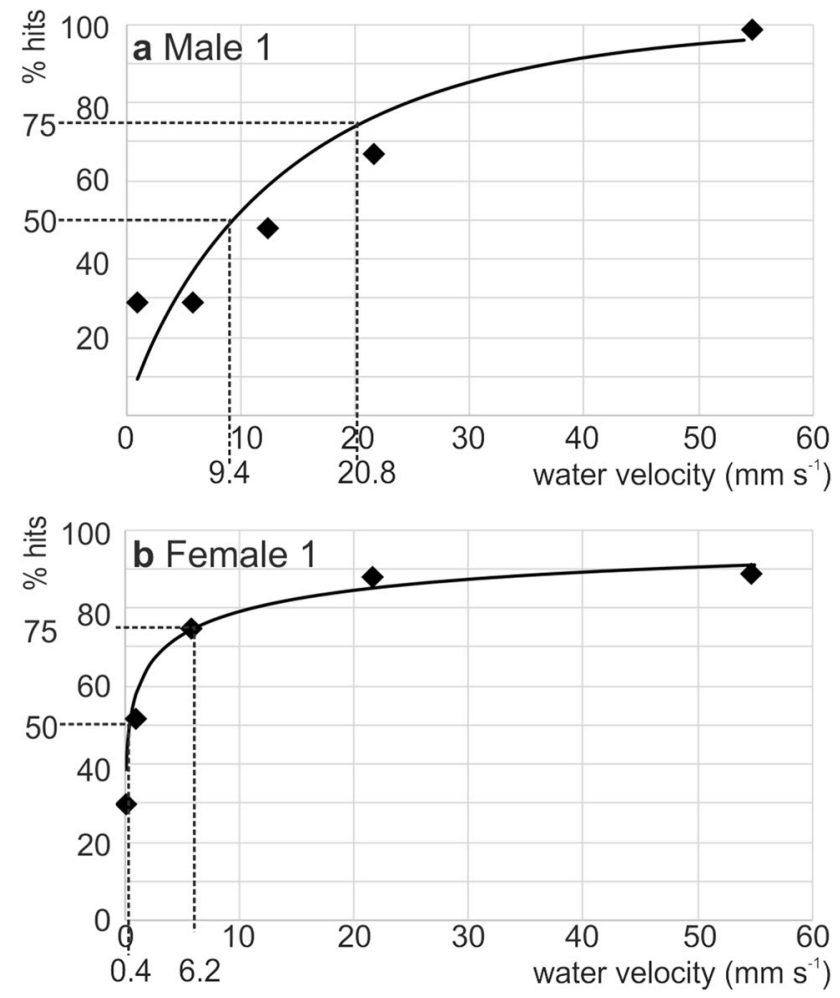

Fig. 5 a, b Psychometric functions of the two water rats that participated in experiment 2. Percentage of correct responses ( $y$ axis) to the complex stimuli as function of stimulus amplitude (maximal water velocity within the reaction time, measured using floating tracer particles). Data are fitted with a Weibull function. The horizontal dashed lines mark $50 \%$ and $75 \%$ correct responses, respectively. The vertical dashed lines indicate the water velocity at which $50 \%$ or $75 \%$ correct responses were obtained. a The male animal (male 1), b the female animal (female 1)

\section{Discussion}

\section{Sensitivity to horizontal water motions}

The present study shows that the Australian water rat $H$. chrysogaster can sense, like the harbour seal P. vitulina (Dehnhardt et al. 1998a, 2001) and the California sea lion Zalphus californianus (Gläser et al. 2011), water motions with its vibrissae. Response thresholds with the hydrodynamic stimuli being detected on $50 \%$ of stimulus trials presented to Hydromys are only a few millimetres per second (in our experimental animals $9.4 \mathrm{~mm} \mathrm{~s}^{-1}$ and $1.0 \mathrm{~mm} \mathrm{~s}^{-1}$, respectively). A moving fish of $20 \mathrm{~cm}$ length may generate subsurface water motion amplitudes above $100 \mathrm{~mm} \mathrm{~s}^{-1}$ (e. g. Bleckmann et al. 1991; Nauen and Lauder 2002; Tytell and Lauder 2008; Lauder 2015). $80 \mathrm{~mm} \mathrm{~s}^{-1}$ have been measured in the wake of an accelerating $86 \mathrm{~mm}$ long fish, and $20 \mathrm{~mm} \mathrm{~s}^{-1}$ in a calmly swimming fish that had a total length of $86 \mathrm{~mm}$ (Hanke and Bleckmann 2004). Fish of this size are part of the prey spectrum of Hydromys. The present study reveals that 
the water motions they cause are much higher in amplitude than necessary to elicit a response in Hydromys. Woollard and McLean (1978) report that Hydromys were commonly observed eating goldfish of $12-14 \mathrm{~cm}$ in length, and estimate from fish scales found in the stomach and intestines of Hydromys that fish of up to 30 or $36 \mathrm{~cm}$ are consumed. The present study does not explicitly demonstrate that Hydromys uses prey-generated water motions for prey detection, however this conclusion is consistent with its vibrissal sensitivity and the sit-and-wait behaviour of the species.

Harbour seals (Phoca vitulina) detect and analyse subsurface water motions not only of the sinusoidally oscillating dipole type (Dehnhardt et al. 1998a), which bear some resemblance with the water movements generated by oscillating body parts, but also direct current water jets (Wieskotten et al. 2011; Niesterok et al. 2017a, b; Krüger et al. 2018). Direct current water jets occur, for example, in the tail wake of fishes (Hanke and Bleckmann 2004; Niesterok and Hanke 2013), where they often form the central part of vortex rings, and in the breathing currents of fishes (Niesterok et al. 2017b). As vortex rings produced by fish tails constitute strong and stable flow structures, they appear to be promising subjects for future studies on the discrimination and directional sensitivity of Hydromys to hydrodynamic stimuli, corresponding to studies on stationary harbour seals (Krüger et al. 2018).

\section{Sensitivity to surface waves}

Surface waves generated by terrestrial insects trapped and struggling at the water surface and by aquatic animals touching the water surface from below, as well as surface waves generated by abiotic sources such as wind or falling objects, have been studied extensively by authors that were interested in predator-prey interactions (e. g. Lang 1980; Bleckmann 1985a, b; reviews by Bleckmann 1994 and Hanke 2020). Surface waves from struggling insects are broadband (typically $0-140 \mathrm{~Hz}$ ) and low in amplitude, and originate from a more or less constant location for an extended time span in the order of seconds. Surface waves from aquatic animals that briefly touch the water surface have narrower frequency bands (typically up to $40 \mathrm{~Hz}$ for waves caused by vertebrates, up to 100 or rarely $140 \mathrm{~Hz}$ for waves caused by insects) and last for less than a second. Thus, the broadband stimuli used in experiment 1 in this study share key characteristics with the surface waves caused by terrestrial insects struggling at the water surface. The single-frequency surface waves used here resemble the surface waves caused by trapped insects only regarding their overall duration and their originating from a constant location, while they were somewhat artificial with regard to their frequency content. Broadband stimuli of 0-50 and $0-100 \mathrm{~Hz}$ used in this study resemble the surface waves caused by aquatic animals regarding their frequency content and their originating from a constant location, while they tend to exceed them in duration. It is remarkable that the water rats did not respond to a variety of surface wave stimuli that were offered and that included close approximations of surface waves generated by insects struggling at the water surface, which are potential prey items.

Contrary to surface feeding fish, aquatic amphibians, whirligig beetles, back swimmers, water striders, fishing spiders (for review see Bleckmann 1994) and crocodiles (Grap et al. 2015), the Australian water rats used in this study did not respond to pure surface waves, but exclusively to the complex hydrodynamic stimuli used in experiment 2 (stimuli 2). The amplitudes of both the sine waves and the broadband stimuli in experiment 1 (waves generated with a vibrating rod) were several orders of magnitude above the sensory thresholds of the surface feeding animals mentioned above. The fact that Hydromys never responded to pure surface waves may be due to a lack of sensitivity or a lack of motivation. We favour the first explanation, because considering the broad prey spectrum of $H$. chrysogaster it is unlikely that the surface waves applied here did not simulate attractive prey. This holds true at least for the large bandwidth stimuli whose frequency content came close to the frequency content of water surface waves generated by terrestrial insects struggling at the water surface (Bleckmann 1985a, b, 1988). An additional hypothesis to be tested in future studies is that Hydromys may be able to learn to detect pure surface waves (stimuli 1) as in experiment 1 after being trained with complex hydrodynamic stimuli (stimuli 2) as in experiment 2. However, if the water rats would respond to stimuli 1 after learning to respond to stimuli 2, we would still conclude that pure surface waves are probably not the adequate stimulus in the ecological context, as there was a striking contrast between not learning to respond to stimuli 1 for four weeks and spontaneously and strongly reacting to stimuli 2 in the very first trial.

The surface waves that were part of stimuli 2 at the 50\% threshold are unlikely to be sufficient to elicit a response. If the $50 \%$ response threshold is expressed in terms of water column height by interpolation, we obtain $25.5 \mathrm{~cm}$ (animal 1) and $9.5 \mathrm{~cm}$ (animal 2), respectively. Surface wave amplitudes of the complex stimuli varied between $435 \pm 143 \mu \mathrm{m}$ ( $25 \mathrm{~cm}$ water column) and $65 \pm 32 \mu \mathrm{m}$ ( $15 \mathrm{~cm}$ water column). Thus, in animal 1, surface wave thresholds in experiment 2 were smaller than the pure surface waves used in experiment 1 by a factor of $2.1(10 \mathrm{~Hz}$ sinus $)$, and $1.6(20 \mathrm{~Hz}$ sinus $)$, albeit larger than the other pure surface waves applied. For animal 2, the surface waves at the behavioural threshold in experiment 2 were smaller than the surface waves in experiment 1 by a factor of $1.8-14$, and thus unlikely to elicit a response alone. It is still possible, however, that the surface waves included in hydrodynamic stimuli 2 may have aided in the detection process. 


\section{Ecological implications}

This pilot study presents results from three (experiment 1 ) or two (experiment 2) individuals of $H$. chrysogaster that were available at the time of the experiments. The limited number of experimental animals does not allow for a survey of intraspecific variation. However, the three (or two, respectively) individuals were apparently normal and healthy representatives of the species and most probably provide typical examples of the sensory abilities of Hydromys; superior abilities in free-ranging conspecifics with extensive experience in the natural habitat cannot be excluded.

Fish, aquatic amphibians, crocodilians, crustaceans, cephalopods, and many semiaquatic insects and fishing spiders (Bleckmann 1994; Soares 2002; Marshall et al. 2014) extract information about their environment from prey-generated hydrodynamic stimuli. Among mammals, harbour seals (Phoca vitulina) not only detect water movements with their vibrissae (Dehnhardt et al. 1998a), but also use vibrissal information to follow the hydrodynamic trails caused by moving objects (Dehnhardt et al. 2001) over a distance where vision is useless (Weiffen et al. 2006). The present study provides the first evidence that a rodent can detect hydrodynamic stimuli. Its hydrodynamic sensitivity is sufficient to sense a fish swimming by, but probably not to detect an insect struggling at the water surface. Most likely the water rat's hydrodynamic perception aims at relatively large prey.

The visual system of Hydromys is adapted to a nocturnal life style. Hydromys is short-sighted and lacks adaptations for underwater vision (M. Schleef and G. Dehnhardt, unpublished). Perception of movement appears to be good (Woollard et al. 1978). This makes it conceivable that prey items, or surface waves caused by prey items, may be perceived visually in bright nights or during daytime while Hydromys is in lurking position, as the sit-and-wait behaviour of Hydromys is not exclusively nocturnal (own observations).

Other senses of Hydromys have not been studied. The outer ear of this water rat is not remarkably different from that of land-living rodents, making it likely that its sense of hearing is especially well developed. Observations in our laboratory suggest that olfactory prey perception may also play a significant role, at least as long as the water rat's head is not submerged. Specifically, the odour of fresh fish in air, which was not part of the regular diet, could induce excited sniffing with the nose raised.

Detection of fluid flow, specifically air flow, by a rodent using its vibrissae has also been reported by Yu et al. (2016, 2019 ) for rats ( $R$. norvegicus). Rats are able to respond to air flow and perform anemotaxis, i.e. orient towards the wind direction. This behaviour should be suited to track down a food source whose odour is carried away by the wind. Similar abilities are conceivable in Hydromys as well.
Considering the natural sit-and-wait behaviour of $H$. chrysogaster (Fig. 1a), the results of our study strongly support the hypothesis that the perception of prey-generated water movements plays a role in foraging in the Australian water rat. Subsurface water motions generated by fish can exceed the water rat's detection thresholds greatly. Fishgenerated surface waves may add to the detection process.

Fishing spiders of the genus Dolomedes as well as semiaquatic insects of the genus Notonecta also attempt to catch small fish passing by (Bleckmann and Lotz 1987; Mail et al. 2018). In these predators, fish catching behaviour is triggered by the surface waves and subsurface water motions caused by fish, but also by any direct incidental contact with a fish. Most likely incidental vibrissal contact with a fish will also trigger prey capture behaviour in Hydromys. However, sensing of hydrodynamic stimuli will significantly extend the detection range of the vibrissal system. To what accuracy the direction and distance of the prey can be localized remains to be investigated. Further important follow-up questions include how Australian water rats may cope with the hydrodynamic noise pervasive in running waters.

Acknowledgements Open Access funding provided by Projekt DEAL. We express our appreciation to Dr. M. Hofmann for his critical comments on an earlier version of the manuscript and his valuable technical support. The experiments comply with the "Principles of animal care" Publication Nr. 85-23, revised 1985 of the National Institute of Health and with German law.

Author contributions SM performed all animal experiments, contributed to designing and establishing the experiments, measured and analysed hydrodynamic stimuli, and wrote her diploma thesis on the subject. GD and HB provided scientific guidance and contributed to data analysis and interpretation. WH provided scientific guidance, analysed data, measured hydrodynamic stimuli, and wrote the manuscript.

Open Access This article is licensed under a Creative Commons Attribution 4.0 International License, which permits use, sharing, adaptation, distribution and reproduction in any medium or format, as long as you give appropriate credit to the original author(s) and the source, provide a link to the Creative Commons licence, and indicate if changes were made. The images or other third party material in this article are included in the article's Creative Commons licence, unless indicated otherwise in a credit line to the material. If material is not included in the article's Creative Commons licence and your intended use is not permitted by statutory regulation or exceeds the permitted use, you will need to obtain permission directly from the copyright holder. To view a copy of this licence, visit http://creativecommons.org/licenses/by/4.0/.

\section{References}

Bleckmann H (1985a) Perception of water surface waves: How surface waves are used for prey identification, prey localization, and intraspecific communication. In: Ottoson O (ed) Progress in sensory physiology. Springer, New York, pp 147-166

Bleckmann H (1985b) Discrimination between prey and non-prey wave signals in the fishing spider Dolomedes triton. In: Kalmring K, 
Elsner N (eds) Acoustic and vibrational communication in insects. Paul Parey, Berlin, pp 215-222

Bleckmann H (1988) Prey identification and prey localization in surface-feeding fish and fishing spiders. In: Atema J, Fay RR, Popper AN, Tavolga WN (eds) Sensory biology of aquatic animals. Springer, New York, Berlin, Heidelberg, London, pp 619-641

Bleckmann H (1994) Reception of hydrodynamic stimuli in aquatic and semiaquatic animals. Gustav Fischer Verlag, Stuttgart, Jena, New York

Bleckmann H, Breithaupt T, Blickhan R, Tautz J (1991) The time course and frequency content of hydrodynamic events caused by moving fish, frogs, and crustaceans. J Comp Physiol A 168:749-757

Bleckmann H, Lotz T (1987) The vertebrate-catching behavior of the fishing spider Dolomedes triton (Araneae, Pisauridae). Anim Behav 35:641-651

Catania KC, Hare JF, Campbell KL (2008) Water shrews detect movement, shape, and smell to find prey underwater. Proc Natl Acad Sci USA 105:571-576

Dehnhardt G (1990) Preliminary results from psychophysical studies on the tactile sensitivity in marine mammals. In: Thomas JA, Kastelein RA (eds) Sensory abilities of cetaceans. Plenum Press, New York, pp 435-446

Dehnhardt G (1994) Tactile size discrimination by a California sea lion (Zalophus californianus) using its mystacial vibrissae. J Comp Physiol A 175:791-800

Dehnhardt G, Dücker G (1996) Tactual discrimination of size and shape by a California sea lion (Zalophus californianus). Anim Learn Behav 24:366-374

Dehnhardt G, Hyvärinen H, Palviainen A, Klauer G (1999) Structure and innervation of the vibrissal follicle-sinus complex in the Australian water rat, Hydromys chrysogaster. J Comp Neurol 411:550-562

Dehnhardt G, Kaminski A (1995) Sensitivity of the mystacial vibrissae of harbour seals (Phoca vitulina) for size differences of actively touched objects. J Exp Biol 198:2317-2323

Dehnhardt G, Mauck B, Bleckmann H (1998a) Seal whiskers detect water movements. Nature 394:235-236

Dehnhardt G, Mauck B, Hanke W, Bleckmann H (2001) Hydrodynamic trail following in harbor seals (Phoca vitulina). Science 293:102-104

Dehnhardt G, Mauck B, Hyvärinen H (1998b) Ambient temperature does not affect the tactile sensitivity of mystacial vibrissae of harbour seals. J Exp Biol 201:3023-3029

Ebara SK, Kumamoto K, Matsuura T, Mazurkiewicz JE, Rice FL (2002) Similarities and differences in the innervation of mystacial vibrissal follicle-sinus complexes in the rat and cat: a confocal microscopic study. J Comp Neurol 449:103-119

Gellermann LW (1933) Chance orders of alternating stimuli in visual discrimination experiments. J Genet Psychol 42:206-208

Gescheider GA (1976) Psychophysics. Method and theory. Lawrence Erlbaum Associates, Hillsdale

Gläser N, Wieskotten S, Otter C, Dehnhardt G, Hanke W (2011) Hydrodynamic trail following in a California sea lion (Zalophus californianus). J Comp Physiol A 197:141-151

Grap NJ, Monzel AS, Kohl T, Bleckmann H (2015) Crocodylus niloticus (Crocodilia) is highly sensitive to water surface waves. Zoology $118: 320-324$

Hanke W (2020) Hydrodynamic stimuli and hydrodynamic noise. In: Fritzsch B (ed) The senses. A comprehensive reference. Elsevier, Amsterdam, Berlin

Hanke W, Bleckmann H (2004) The hydrodynamic trails of Lepomis gibbosus (Centrarchidae), Colomesus psittacus (Tetraodontidae) and Thysochromis ansorgii (Cichlidae) measured with Scanning Particle Image Velocimetry. J Exp Biol 207:1585-1596

Heydon MJ, Ghaffar N (1997) Records of otter civets (Cynogale bennettii) from northern Borneo. Small Carniv Conserv 16:27
Krüger Y, Hanke W, Miersch L, Dehnhardt G (2018) Detection and direction discrimination of single vortex rings by harbour seals (Phoca vitulina). J Exp Biol 221:170753

Lang HH (1980) Surface-wave discrimination between prey and nonprey by the back swimmer Notonecta glauca L. (Hemiptera, Heteroptera). Behav Ecol Sociobiol 6:233-246

Lauder GV (2015) Fish locomotion: recent advances and new directions. In: Carlson CA, Giovannoni SJ (eds) Annual review of marine science, vol 7. Annual Reviews, Palo Alto, pp 521-545

Mail M, Klein A, Bleckmann H, Schmitz A, Scherer T, Ruhr PT, Lovric G, Frohlingsdorf R, Gorb SN, Barthlott W (2018) A new bioinspired method for pressure and flow sensing based on the underwater air-retaining surface of the backswimmer Notonecta. Beilstein J Nanotechnol 9:3039-3047

Marshall CD, Wieskotten S, Hanke W, Hanke FD, Marsh A, Kot B, Dehnhardt G (2014) Feeding kinematics, suction, and hydraulic jetting performance of harbor seals (Phoca vitulina). PLoS ONE 9(1):e86710

McNally J (1960) The biology of the water rat Hydromys chryogaster Geoffroy (Muridae: Hydromyinae) in Victoria. Austr J Zool 8:170-180

Nauen JC, Lauder GV (2002) Quantification of the wake of a rainbow trout using three-dimensional stereoscopic particle image velocimetry. J Exp Biol 205:3271-3279

Niesterok B, Dehnhardt G, Hanke W (2017a) Hydrodynamic sensory threshold in harbour seals (Phoca vitulina) for artificial flatfish breathing currents. J Exp Biol 220:2364-2371

Niesterok B, Hanke W (2013) Hydrodynamic patterns from fast-starts in teleost fish and their possible relevance to predator-prey interactions. J Comp Physiol A 199:139-149

Niesterok B, Krüger Y, Wieskotten S, Dehnhardt G, Hanke W (2017b) Hydrodynamic detection and localization of artificial flatfish breathing currents by harbour seals (Phoca vitulina). J Exp Biol 220:174-185

Seidensticker J, Lumpkin S (1991) Great cats-majestic creatures of the wild. Rodale Press, Emmaus

Soares D (2002) An ancient sensory organ in crocodilians-waiting alligators can detect silent ripples in the water even in total darkness. Nature 417:241-242

Terrace HS (1963) Errorless discrimination learning in pigeon-effects of chlorpromazine and imipramine. Science 140:318-319

Tytell ED, Lauder GV (2008) Hydrodynamics of the escape response in bluegill sunfish, Lepomis macrochirus. J Exp Biol 211:3359-3369

Weiffen M, Möller B, Mauck B, Dehnhardt G (2006) Effect of water turbidity on the visual acuity of harbor seals (Phoca vitulina). Vision Res 46:1777-1783

Wieskotten S, Dehnhardt G, Mauck B, Miersch L, Hanke W (2010) The impact of glide phases on the trackability of hydrodynamic trails in harbour seals (Phoca vitulina). J Exp Biol 213:3734-3740

Wieskotten S, Mauck B, Miersch L, Dehnhardt G, Hanke W (2011) Hydrodynamic discrimination of wakes caused by objects of different size or shape in a harbour seal (Phoca vitulina). J Exp Biol 214:1922-1930

Woollard P, Vestjens WJM, MacLean L (1978) The ecology of the Eastern Water Rat Hydromys chrysogaster at Griffith, N.S.W.: Food and feeding habits. Aust Wildl Res 5:59-73

Yu YSW, Bush NE, Hartmann MJZ (2019) Whisker vibrations and the activity of trigeminal primary afferents in response to airflow. $\mathrm{J}$ Neurosci 39:5881-5896

Yu YSW, Graff MM, Bresee CS, Man YB, Hartmann MJZ (2016) Whiskers aid anemotaxis in rats. Sci Adv 2:7

Publisher's Note Springer Nature remains neutral with regard to jurisdictional claims in published maps and institutional affiliations. 